
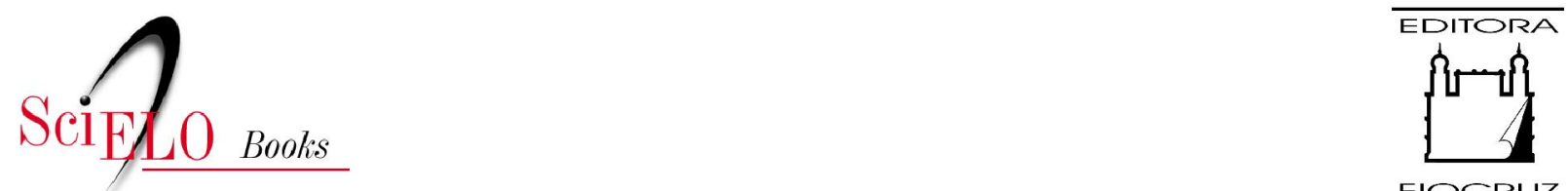

FIOCRUZ

\title{
2 - A experiência brasileira de estímulo à fixação de médicos no interior
}

\author{
Romulo Maciel Filho \\ Maria Alice Fernandes Branco
}

\section{SciELO Books / SciELO Livros / SciELO Libros}

MACIEL FILHO, R., and BRANCO, M. A. F. A experiência brasileira de estímulo à fixação de médicos no interior. In: Rumo ao interior: médicos, saúde da família e mercado de trabalho [online]. Rio de Janeiro: Editora Fiocruz, 2008, pp. 49-82. ISBN: 978-85-7541-601-3. Available from: doi: $\underline{10.7476 / 9788575416013.004}$. Also available in ePUB from: http://books.scielo.org/id/64g49/epub/maciel-9788575416013.epub.

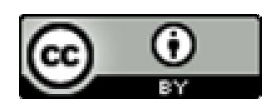

All the contents of this work, except where otherwise noted, is licensed under a Creative Commons Attribution $\underline{4.0 \text { International license. }}$

Todo o conteúdo deste trabalho, exceto quando houver ressalva, é publicado sob a licença Creative Commons Atribição 4.0.

Todo el contenido de esta obra, excepto donde se indique lo contrario, está bajo licencia de la licencia Creative Commons Reconocimento 4.0. 


\section{A Experiência Brasileira de Estímulo à Fixação de Médicos no Interior}

Neste capítulo são descritas as intervenções que o Brasil adotou para fazer frente ao problema da má distribuição de médicos e outros profissionais no território nacional. A descrição dessas experiências tem caráter ilustrativo, com a finalidade de conhecer que tipo de estratégias já foram empregadas em nosso país. Tais intervenções, iniciadas na década de 1960, foram estruturadas sob a forma de programas governamentais. Foram quatro os programas que incluíram a interiorização de profissionais dentre suas metas: o Projeto Rondon, o Programa de Interiorização das Ações de Saúde e Saneamento (Piass), o Programa de Interiorização do Sistema Único de Saúde (Pisus) e o Programa de Interiorização do Trabalho em Saúde (Pits).

Antes, porém, de apresentar essas experiências, é fundamental contextualizar como o problema da má distribuição foi sendo tratado no debate político e acadêmico, a fim de compreender os referenciais que nortearam a atuação governamental perante o problema e a criação desses programas como estratégias de intervenção.

As intervenções governamentais são fruto de um processo de formulação de políticas, que se inicia com a definição da agenda. Como os recursos públicos são escassos para atender a todas as necessidades, são alocados segundo princípios muito variados. Mas, em geral, é possível afirmar que a primeira decisão refere-se a como alocá-los entre os diferentes âmbitos da ação pública; em seguida, entre setores sociais, como saúde, educação e outros, e, finalmente, entre programas de uma determinada área (Cohen \& Franco, 2004).

Planos, programas e projetos compõem, portanto, o conjunto de estratégias da atuação governamental e expressam as políticas adotadas pelo Estado para fazer frente às necessidades sociais. Os três são assim definidos por Cohen e Franco (2004: 86 - grifos dos autores): 
Um projeto é um empreendimento planejado que consiste num conjunto de atividades inter-relacionadas e coordenadas para alcançar objetivos específicos (...).

Um programa é um conjunto de projetos que perseguem os mesmos objetivos. Estabelece as prioridades de intervenção, identifica e ordena os projetos, define o âmbito institucional e aloca os recursos a serem utilizados. (...)

Um plano é a soma de programas que procuram objetivos comuns, ordena os objetivos gerais e os desagrega em objetivos específicos, que constituirão por sua vez os objetivos gerais dos programas. Determina o modelo de alocação de recursos resultantes da decisão política. (...)

Mesmo quando o plano esteja ausente, sempre existirão os outros dois elos da cadeia [programas e projetos].

No caso do setor saúde, não há dúvida de que o Estado é uma das principais - senão a principal - fontes normativas do trabalho médico, por seu papel de agente racionalizador e modernizador. O Estado não apenas incrementa o setor saúde, por meio da alocação de recursos, como orienta as definições básicas dos lugares destinados à assistência médica, das atividades que determinam o caráter do trabalho médico e dos marcos institucionais que regem a prestação dos serviços médicos.

A intervenção do Estado na prestação de atenção à saúde tem dois principais tipos de efeito no mercado de trabalho para o médico. Um é de ordem quantitativa e se refere ao aumento ou diminuição da demanda por este profissional. O outro tem uma dimensão qualitativa e está ligado às modalidades de organização da atenção médica nos setores público e privado (Donnangelo, 1975).

Quanto maior o lugar que o Estado ocupa na prestação direta dos serviços de saúde, mais acentuados serão os efeitos, que vão desde a repercussão sobre os próprios paradigmas que regem a formação e a prática médica até a redução na autonomia profissional, ao transformar o médico em empregado assalariado.

A forma como o Estado brasileiro tem lidado com essas questões, no que se refere ao problema da má distribuição de médicos no país, têm oscilado entre intervenções ora focadas na extensão universitária, ora na oferta de incentivos e benefícios para os profissionais que se disponham a atuar nas áreas mais carentes e remotas do país. Nenhuma dessas formas, no entanto, minimizou efetivamente a má distribuição 
de médicos, ao longo da trajetória de reformas e transformações da política de saúde.

Essas mudanças na política de saúde foram geradas, como ressalta Pierantoni (2000: 34-35):

muito mais como produto das transformações sociais e das demandas geradas pela implementação de sucessivas políticas econômicas. A Saúde aparece como coadjuvante, com ações implementadas a partir de cada momento político, e não como processo que consolida uma rede e um sistema adequado para as necessidades de uma população desigualmente distribuída do ponto de vista geográfico, econômico e cultural. Mais ainda, essas desigualdades são agravadas pela acentuada diferença na construção e acesso a equipamentos sociais que possibilitem melhores condições de saúde (...).

Lidar com essas desigualdades tem sido, historicamente, um desafio. No que se refere à falta de médicos nas áreas mais carentes, se considerarmos que o Ministério da Saúde foi criado em 1953, e que já chegamos ao século XXI, percebemos que a disponibilidade de médicos nessas áreas se mantém como um problema atual para a política de saúde há mais de meio século. E tem raízes históricas, já analisadas no primeiro capítulo.

A $3^{\text {a }}$ Conferência Nacional de Saúde, realizada em 1963, foi a primeira a se debruçar mais detalhadamente sobre o problema da má distribuição de médicos no país. Em seu relatório final, o tema "O problema de pessoal" é iniciado com a seguinte pergunta: "Como vai ser resolvida a presença de médicos nos municípios?” (Brasil, 1993a: 20). À indagação segue-se o diagnóstico:

Seria ingenuidade pretender mandar médicos em grande número para o interior. Não só no Brasil, como no mundo inteiro, o que se vem verificando é a concentração cada dia maior de profissionais da medicina nos grandes centros. $\mathrm{O}$ avanço da tecnologia médica, a especialização, a aparelhagem necessária à prática da medicina moderna, praticamente conduzem a que os médicos só desejem trabalhar em grandes centros, onde contam com todos os recursos e verdadeiras equipes. Além do mais, com o enriquecimento dos habitantes das metrópoles, amplia-se cada dia o mercado de trabalho dos médicos nas grandes concentrações 
demográficas, de forma que não há como, nas condições atuais, levar médicos para atender às populações do interior.

A Conferência foi realizada no mesmo ano da Primeira Reunião de Ministros de Saúde das Américas, tendo sido debatidos nos dois eventos, no campo dos recursos humanos, os mesmos problemas: "carência e má distribuição de mão-de-obra, além da necessidade de traçar programas de capacitação, fixação e interiorização de profissionais de saúde nas regiões menos favorecidas" (Sayd, Vieira Jr. \& Velandia, 1998: 171).

Realizada quatro anos depois, em 1967, a Conferência seguinte, já em plena ditadura militar, foi convocada com a finalidade explícita de debater o tema, dada a premência de resolvê-lo, tendo por objetivo "formular sugestões para uma política permanente de avaliação de recursos humanos, tendo em vista a formação dos contingentes de pessoal de que o país carece para o desenvolvimento das suas atividades de saúde" (Brasil, 1967: 11).

Na ocasião, o meio acadêmico ressaltava a necessidade de que o Ministério da Saúde investisse na produção de dados sobre os recursos humanos em saúde como forma de obter subsídios mais consistentes para a formulação de políticas que orientassem as relações entre a oferta e a demanda desses profissionais, tanto qualitativa quanto quantitativamente. Essa foi, aliás, a tônica do debate acadêmico, nos anos 60, não apenas no Brasil, mas no cenário internacional. De um lado, havia que enfrentar a chamada 'crise de pessoal' por que passava a saúde; de outro, o sistema de formação se caracterizava pela falta de racionalidade e desconexão com as necessidades reais do setor. Como conseqüência, abriu-se todo um campo de investigação e debate sobre o planejamento de recursos humanos - no Brasil e em diversos países com a intenção de elaborar métodos que permitissem determinar a quantidade de pessoal necessário em cada categoria profissional.

A primeira referência sobre o planejamento de recursos humanos em saúde surgiu em 1958, como parte de uma publicação científica da Organização Pan-Americana da Saúde (Opas). Pouco depois, em 1961, em reunião da Organização dos Estados Americanos (OEA, foi acordada a urgência de se determinar o número de profissionais necessários em cada país; e na Reunião de Ministros da Saúde, de 1963, a referência especial recaiu sobre a importância do planejamento da formação médica (Vidal, 1984). 
Paralelamente, teve início o planejamento em saúde, com a criação do método Cendes-Opas. O Centro Pan-Americano de Planejamento em Saúde, da Opas, desenvolveu métodos globais de planejamento, que ressaltavam a importância dos recursos humanos. O próprio Plano Decenal de Saúde para as Américas, para o período 1971-1980, estabeleceu uma série de metas quantitativas para diferentes categorias profissionais, embora com poucas referências à relação estrutural dessas metas com mudanças nos programas e serviços de saúde (Vidal, 1984).

A ênfase recaiu sobre a importância dos métodos de projeção e cálculo dos recursos humanos necessários para atender às demandas do setor saúde, nas distintas regiões de um país. Com base em indicadores demográficos e socioeconômicos, essas orientações e os diversos estudos a partir delas produzidos se restringiram a um enfoque quantitativo de projeção de tendências, em busca de maior racionalidade científica para o planejamento de recursos humanos em saúde, sem tratar das implicações políticas aí embutidas. Descuidou-se do fato de que uma política de recursos humanos exige a consideração de um conjunto de variáveis que atuam simultaneamente e interagem entre si, em um contexto complexo e fortemente influenciado por fatores culturais e decisões políticas, que torna falaciosas as projeções de cunho eminentemente estatístico.

De modo geral, esses estudos não foram bem sucedidos, uma vez que não permitiam ir além de um enfoque quantitativo, que projetava as tendências existentes, mantendo a rigidez do então sistema de saúde e das instituições formadoras tal como se configuravam naquele momento.

Esse tipo de enfoque, com base em estudos de demanda-manifesta e projeção de oferta, refletia a corrente de pensamento que dominou a saúde pública nos anos 50 e 60. Essa corrente utilizou como argumento a busca de racionalidade e eficiência, consideradas inerentes a um enfoque científico, e transpôs para a saúde as técnicas utilizadas no campo da economia.

A partir da década de 1970, embora a abordagem mais racionalista ainda tenha se mantido com alguma força, destacando a influência dos recursos humanos sobre os custos dos serviços de saúde, o debate passou a evidenciar, cada vez mais, a dimensão política do tema, ressaltando sua forte relação com a necessidade de mudanças culturais, sociais e 
econômicas. Começam a ganhar relevo as discussões sobre o acesso da população a esses serviços, a formação desses profissionais, a realidade socioeconômica, o corporativismo, a política governamental, o processo educacional, os referenciais socioculturais, dentre outros aspectos.

De forma convergente com esse debate, o Ministério da Educação e Cultura (MEC) elaborou, em 1976, o Estudo sobre a Formação e Utilização dos Recursos Humanos na Área da Saúde (Brasil, 1976b), com a contribuição do Ministério da Saúde e do Ministério da Previdência e Assistência Social (MPAS). Seu objetivo era "propor diretrizes para as ações que permitam a correção das principais distorções que vêm ocorrendo na preparação e utilização de recursos humanos no setor Saúde" (Brasil, 1976b: 9).

A partir da análise de diagnósticos já existentes, o estudo atribuía as insuficiências na prestação de assistência médica a fatores demográficos (como o crescimento populacional acelerado e o movimento migratório), socioculturais, políticos e tecnológicos, e recomendava que a formação dos profissionais de saúde deveria pautarse pelas reais necessidades da população, de forma a "inserir o ensino de saúde no contexto socioeconômico, cultural e político do Brasil e de suas regiões" (Brasil, 1976b: 11).

Com relação à formação médica, afirmava que o estoque desses profissionais já ultrapassava as projeções para 1980 (1.225 hab./médico), superando as metas do Plano Decenal, e destacava a inadequação do ensino médico à realidade brasileira. Para enfrentar o problema, propunha reformas curriculares e experiências práticas em medicina comunitária e saúde pública, além de maior articulação entre os ministérios da Educação, Saúde e Previdência.

Mas embora as ações do Estado implementadas no campo da saúde, no período desenvolvimentista, tenham aumentado a oferta de médicos e ampliado o mercado de trabalho, inclusive nas regiões mais desfavorecidas, foram insuficientes, por si só, para enfrentar o problema da má distribuição desses profissionais no território nacional:

as regiões que apresentaram maiores incrementos no número de médicos foram: Norte (701,84\%); Centro-Oeste $(330,45 \%)$ e Sul (164,09\%). As duas primeiras, no entanto, ainda apresentam um baixo contingente destes profissionais com relação à magnitude de suas populações. (...) Apesar dos esforços do Governo Federal, 
do Ministério da Saúde e das Secretarias Estaduais em aparelharem a rede pública de saúde dos estados nordestinos, o baixo poder aquisitivo da população tem impedido uma maior fixação de médicos na região. Como salientou Celso Furtado, em artigo publicado no Caderno Especial do Jornal do Brasil de 20.11.83, 'se é verdade que o produto bruto do Nordeste quadruplicou entre 1960 e 1980, dois terços da população trabalhadora permanecem com uma renda igual ou inferior a um salário mínimo'. Portanto, na atual estrutura privatizante da atenção médica no Brasil, somente uma melhoria substancial da distribuição dos rendimentos da população poderia resolver o problema da fixação de médicos nas regiões mais carentes. (Medici, 1985: 57)

Com a realização, em 1986, da Conferência Nacional de Recursos Humanos em Saúde, observa-se uma mudança fundamental no eixo de discussão, que se desloca do dimensionamento quantitativo para a crítica à ausência de uma política de recursos humanos. Ainda hoje, as questões mais prementes do campo dos recursos humanos em saúde não foram objeto de intervenções estatais consistentes, duradouras e congruentes com os princípios da Reforma Sanitária.

A partir de agora serão abordadas as estratégias adotadas pelo Estado brasileiro para enfrentar o problema da má distribuição de médicos no país; identificando-as segundo o recorte político que as fundamentou: ditatorial ou democrático.

\section{Estratégias da Ditadura Militar}

Iniciado em 1964, com o golpe militar de 31 de março, o período ditatorial no Brasil estendeu-se até o ano de 1978, quando se abriu o caminho para a redemocratização. Nesse período, foram implantados dois programas que tiveram a interiorização de profissionais como uma de suas metas: o Projeto Rondon e o Programa de Interiorização das Ações de Saúde e Saneamento (Piass).

O Projeto Rondon

Criado em 1968, pelo decreto n. 62.927, o Projeto Rondon foi o primeiro grande programa de extensão universitária de abrangência nacional instituído pelo governo brasileiro, tendo como finalidade "promover estágios de serviço para estudantes universitários, 
objetivando conduzir a juventude a participar do processo de integração nacional" (Brasil, 1968). A participação no Projeto, de caráter voluntário, abrangia estudantes de todos os cursos universitários para desempenhar atividades específicas de seu campo de formação em localidades do interior do país, desprovidas de infra-estrutura econômica e social.

Em publicação elaborada pelos formuladores do Projeto Rondon, sua criação é contextualizada segundo a lógica doutrinária da ditadura militar:

Na segunda metade da década de 60 , o inconformismo juvenil - fermento das grandes campanhas libertárias em tôdas as épocas e em tôdos os países - radicalizou-se numa escalada mundial de manifestações públicas, protestos, conflitos e movimentos de massa.(...)

No Brasil um fato era latente. Havia uma enorme predisposição da parte dos jovens de contribuir de alguma forma no processo brasileiro.

O que se fazia necessário era mostrar-lhes o caminho sério e construtivo da participação real nos destinos do Brasil.

Atravessávamos uma época em que mais do que nunca necessitávamos do trabalho devotado, do altruísmo, da convicção patriótica, de reformas é claro, desde que calcadas na realidade de nossa problemática.

Êste quadro político-institucional brasileiro mereceu a atenção dos governantes e das universidades e foi objeto do seminário promovido pela ECEME (Escola De Comando do Estado-Maior do Exército) e universidades do Estado da Guanabara em outubro/ novembro de 1966.

Nêle estiveram presentes estudiosos do problema educacional brasileiro, nascendo nos debates, e cristalizando-se nas conclusões, a necessidade imperiosa de levar os estudantes universitários à participação realista no esfôrço desenvolvimentista brasileiro. (...)

O caminho estava começando a ser apontado: os estudantes viveriam e sentiriam em tôda a sua chocante realidade a vida no interior do Brasil.

O desafio foi aceito por todos os que se empenhavam na idéia: estava lançada a semente do que viria a ser a maior experiência sociológica brasileira - o PROJETo Rondon. (Brasil, 1972: 8-9) 
O lema do Projeto Rondon - "Integrar para não Entregar" - teve como inspiração uma frase do Capitão Lauro Bastos Filho, do $5^{\circ}$ Batalhão do Exército, de Rondônia: "O batalhão está trabalhando dia e noite para integrar a região amazônica e não entregá-la à cobiça, à miséria e ao pauperismo" (Brasil, 1972: 15).

Assim, a palavra de ordem do Projeto Rondon foi 'integração': "Integração geográfica, social e econômica. Integração também de pensamento, de atitudes, de classes e gerações. Integração no plano material e ideológico para o trabalho comum de construção de um novo Brasil" (Brasil, 1972: 5).

Após uma experiência-piloto, realizada em Rondônia, em 1967, da qual participaram 31 estudantes de medicina, engenharia, geociências, e documentação e comunicação, o Projeto Rondon foi efetivamente implantado a partir do já citado decreto n. 62.927, que criou o 'Grupo de Trabalho Projeto Rondon', responsável pela sua condução. Compunham este grupo representantes dos seguintes órgãos: Ministério do Interior, Ministério da Educação e Cultura, Ministério da Marinha, Ministério do Exército, Ministério da Aeronáutica, Ministério dos Transportes, Ministério da Agricultura, Ministério do Planejamento e Coordenação Geral, Ministério da Saúde, Movimento Universitário de Desenvolvimento Econômico e Social (Mudes), Conselho de Reitores (representando as entidades de ensino superior) e a então Universidade do Estado da Guanabara (UEG), em função de sua participação pioneira na experiência-piloto.

Em novembro de 1970, o decreto n. 67.505 transformou o ‘Grupo de Trabalho Projeto Rondon’ em órgão autônomo da administração direta, subordinado ao Ministério do Interior, com autonomia administrativa e financeira, passando a denominar-se simplesmente 'Projeto Rondon' (Brasil, 1970). Sua autonomia financeira foi assegurada por meio da instituição de um fundo específico, o Fundo do Projeto Rondon (FunRondon). Cinco anos depois, em dezembro de 1975, a lei n. 6.310 alçou o Projeto Rondon à categoria de Fundação, ainda subordinada ao Ministério do Interior, mas com orçamento e patrimônio próprios e personalidade jurídica de direito privado, passando a denominar-se Fundação Projeto Rondon, tendo sido extinto o FunRondon. A mesma lei estabeleceu como objetivos básicos do Projeto Rondon: 
I - no campo do desenvolvimento e da integração nacional:

a) colaborar com o Ministério da Educação e Cultura na organização, implantação e coordenação de estágios de estudantes, no interior do país;

b) colaborar na execução da política de integração nacional, em consonância com os planos de desenvolvimento;

c) promover ou participar de programas de desenvolvimento comunitário com as populações interioranas.

II - no campo do mercado de trabalho e mão-de-obra:

a) promover, com os estágios de universitários, o conhecimento das condições do interior do país, abrindo perspectivas para a interiorização e fixação de técnicos de nível superior nas áreas em que atuarem;

b) desenvolver, junto às populações carentes, o treinamento especializado de nível médio, incentivando o mercado de trabalho e o aprimoramento da mão-de-obra qualificada;

c) promover, juntamente com os órgãos especializados, a abertura de novos mercados de trabalho;

d) promover a interiorização de técnicos em áreas menos desenvolvidas do Território Nacional.

III - no campo da pesquisa e preparação de recursos humanos:

a) contribuir para a promoção, coordenação e realização de pesquisas voltadas para o conhecimento da realidade nacional;

b) contribuir para a preparação dos recursos humanos necessários ao desenvolvimento. (Brasil, 1975a)

Considerado como atividade curricular voluntária, o estágio no Projeto Rondon incluía a participação dos corpos discente e docente na preparação e no planejamento das atividades. Os estágios deviam ser prestados no período das férias escolares, nos meses de janeiro ou julho. Dessa forma, a cada seis meses, novas equipes integravam projetos específicos.

O Projeto possuía uma estrutura de funcionamento baseada em uma coordenação geral, de âmbito nacional; e coordenações regionais, estaduais e de área. Para consolidar seus objetivos, foram criados diferentes programas e operações, vinculados a quatro grandes eixos: 'Conhecimento da realidade nacional', 'Integração nacional', 'Desenvolvimento' e 'Interiorização'. 
Com relação às operações, além daquelas de caráter nacional (realizadas nas férias de janeiro e fevereiro, de execução complexa e elevado custo), foram criadas as operações regionais (executadas nas férias do meio do ano, de realização mais simples e menor custo), organizadas e operacionalizadas pelas coordenações estaduais; e as operações locais (em qualquer época do ano e quase sempre por iniciativa das próprias universidades) (Rodrigues, s.d.).

Ainda segundo Rodrigues (s.d.), pouco a pouco, a universidade, como instituição, foi assumindo uma maior participação nas atividades do Projeto Rondon, sendo o 'Campus avançado' a forma como se materializou esse maior envolvimento direto. Os Campi avançados funcionavam como extensões das universidades, na condição de locais de estágios, em pontos estrategicamente selecionados nas regiões menos desenvolvidas do país. Sua criação tinha um duplo objetivo: 1) propiciar aos universitários o aprendizado por meio da prestação de serviços técnico-profissionais a partir de programas supervisionados por docentes, em contato com a realidade local, proporcionando a interiorização do ensino universitário e da tecnologia; 2) transformar as regiões onde se desenvolviam esses estágios em pólos de desenvolvimento integrado, com a articulação entre órgãos da administração local e regional. Os Campi avançados funcionavam, assim, como órgãos de assessoramento de pesquisa, experimentação, planejamento e execução dos projetos que ali se desenvolviam.

Em seminário promovido em 1979 para avaliar os primeiros dez anos do Projeto Rondon, alguns aspectos do funcionamento dos 'Campi avançados' foram objeto de críticas por parte do Conselho Federal de Educação (CFE):

em muitos casos, os 'Campi' avançados de universidades de outras regiões do país que se situam na Amazônia operam praticamente como enclaves culturais, algo que se torna isolado, que não se comunica, que não se articula com as suas congêneres locais e que, conseqüentemente, não as beneficia, ou que as beneficia numa escala muito reduzida (...) a preocupação fundamental seria a de rever este tipo de presença de universitário do sul, do sudeste do país, por exemplo, na Amazônia. (...) as universidades do sul e do sudeste do país se beneficiariam de uma vivência que o corpo docente, os administradores, os alunos das universidades locais lhes poderiam transmitir em razão da própria origem, do próprio 
fato de ali terem nascido e se criado na região e, portanto, de estarem nela culturalmente integrados. Em alguns casos temos notícias de situações surgidas com vinda de universitários de grandes centros urbanos do país para pequenas comunidades do interior, em que esse simples transplante de pessoas que têm uma outra origem e que vêm de outro ambiente cultural cria, em determinadas situações, um verdadeiro choque cultural, às vezes profundo e nem sempre fácil de controlar. (CFE, 1979: 36)

Como decorrência das Operações Nacionais e da atuação dos 'Campi avançados', os programas de interiorização passaram a ser incentivados. Com base em estímulos para a interiorização de profissionais de nível superior, esses programas eram destinados tanto para os profissionais liberais quanto para os servidores públicos que desejassem atuar junto às prefeituras e aos órgãos da administração estadual e federal existentes na região. Essa atuação se dava mediante um vínculo salarial com o Projeto Rondon, por um período máximo de 12 meses. Além disso, havia incentivos para apoio a esses profissionais, como créditos especiais para aqueles que desejassem permanecer com seu exercício profissional nesses municípios ou regiões, destinados à aquisição da casa própria, de equipamentos para consultórios/escritórios ou para a implantação de atividades econômicas privadas (Rodrigues, s.d.).

Os programas de interiorização foram intermitentes durante a trajetória do Projeto Rondon, enfrentando problemas debatidos no seminário anteriormente citado e assim então resumidos pelo CFE:

O problema do Brasil no setor de saúde, para exemplificar, não consiste em apenas formar mais médicos, mas distribuí-los de maneira adequada pelas regiões mais carentes desses profissionais. Mas o médico não atua sozinho, precisa apoiar-se numa infra-estrutura operacional que envolve, além de outros, os Ministérios da Educação e Cultura, do Interior e da Saúde. O problema se coloca não apenas em relação à medicina, mas a várias áreas onde existem profissionais formados e sem emprego, concentrados nas grandes cidades, e, de outra parte, inúmeras regiões totalmente desassistidas. Esse é um aspecto que diz respeito a este Conselho - e é essa a tática que estamos procurando adotar - que é a de colocar os cursos onde profissionais respectivos devem ser formados, onde exista para eles, mercado de trabalho. 
A questão da interiorização do profissional não é, pois, apenas do Projeto Rondon, mas também do Conselho Federal de Educação, procurando, além da elevação do nível cultural das regiões interioranas, assegurar trabalho aos profissionais de nível superior e assistência às populações necessitadas. (CFE, 1979: 35)

O tema manteve-se como permanente preocupação no âmbito do Projeto Rondon, como é possível constatar em outras intervenções, no mesmo seminário, como esta:

no que diz respeito à fixação, à interiorização - (...) uma das preocupações que estão sendo reativadas dentro do Projeto Rondon - já agora do profissional formado (...) este é evidentemente um desafio que extrapola ao âmbito específico de atuação do Projeto Rondon. (...) há pelo menos três ou quatro anos realizam-se no MEC estudos, posteriormente discutidos com outros ministérios e levados à consideração do Estado-Maior das Forças Armadas, sobre a possibilidade de se articular, como que de se acoplar a legislação do serviço militar obrigatório, à criação de um Serviço Civil Social. Assim se propôs chamar a época em que o universitário cumpriria os seus deveres para com a legislação militar, substituídos pela prestação, por um período a ser fixado e que poderia ser de um ou dois anos, de um serviço profissional, após formado, às comunidades interioranas. Isto poderia garantir, em primeiro lugar, a presença permanente do profissional na região, embora com a sua substituição periódica e regular, em determinados campos de atividades nessas comunidades mais desassistidas do interior, evitando-se, assim, o inconveniente da falta de continuidade por ausência de novos candidatos voluntários para substituírem os que se encontravam participando de programas dessa natureza. Enfim, um sistema de incentivo, de estímulos que podem assumir muitas formas e que podem, a par desses casos de voluntariados e de decisão pessoal de permanecer definitivamente no local, onde o jovem esteve ainda como universitário, assegurar a presença permanente dos profissionais de que a comunidade precisa para garantir um nível de vida mais digno, menos carente das coisas mais básicas de que uma população tem necessidade. (CFE, 1979: 36)

Além do Serviço Civil Social obrigatório, outras propostas foram sugeridas no evento: 1) vincular a fixação e a interiorização do 
profissional oriundo do ensino universitário público e gratuito a um determinado número de anos de prestação de serviços; 2) criar incentivos para estimular empreendimentos em diversos setores da economia, nas áreas mais carentes e desfavorecidas; 3 ) instituir o Serviço Cívico Social, de caráter voluntário, mediante estímulos e benefícios, como isenções de serviços e oferta de facilidades em termos de futuro profissional (CFE, 1979).

Com o término do regime militar, em 1984, e o início do processo de redemocratização do país, o Projeto Rondon entrou em processo de extinção, encerrando suas atividades em 1989. Na avaliação de Rodrigues (s.d.), além do esvaziamento político em torno da doutrina que fundamentava o Projeto, gerado pelo novo contexto político do país, outros fatores foram decisivos para sua extinção:

As utilizações indevidas de suas estruturas, os abusos no manuseio dos recursos financeiros para outros fins, aproveitandose as facilidades administrativas que o Projeto oferecia, os desvirtuamentos de suas finalidades, que passaram a ocorrer desde então, além das diversas ações de pretexto investigatório que se desenvolveram visando alguns de seus dirigentes na ocasião, tinham, na realidade, como objetivo, desacreditar o movimento junto à opinião pública. Apenas como um exemplo desse desvirtuamento, citamos o 'rateamento' de seus cargos de direção entre os diferentes partidos políticos que apoiavam o governo que se instalava. Cresceram os 'apetites políticos' e o Rondon 'era um prato cheio'.... inclusive pelos dividendos políticos que o próprio cargo de Presidente da Fundação oferecia. (Rodrigues, s.d.: s.p.)

Durante seus 22 anos de existência, o Projeto Rondon contemplou milhares de municípios - majoritariamente localizados nas regiões Norte, Nordeste e Centro-Oeste - que receberam atendimentos e serviços nas áreas de saúde, educação, agropecuária, engenharia, arquitetura e outras. Participaram do Projeto cerca de 350 mil universitários e 13 mil professores. $\mathrm{Na}$ área da saúde, foram realizados atendimentos médicos, odontológicos, de enfermagem, vacinação, combate a endemias, pesquisas, planejamento e educação sanitária (Brasil, 1972; Rodrigues, s.d).

Do ponto de vista político, a principal crítica ao Projeto Rondon consistiu em classificá-lo como "um movimento criado pelos governos militares para anestesiar a juventude universitária 


\section{(...)'; ou então, 'como uma forma fascista de mobilização dos}

jovens (...)', ou ainda, 'como um instrumento da propaganda oficial do autoritarismo (...)"'. (Rodrigues, s.d., s.p. - grifos do autor).

Do ponto de vista técnico, as críticas recaíam sobre o curto tempo de permanência dos universitários nas comunidades, além do fato de que, dado seu caráter voluntário, havia dificuldades para evitar a descontinuidade de participação de estudantes de alguns cursos, como por exemplo, de medicina: “(...) esse trabalho no período escolar é um trabalho efêmero, é um trabalho condicionado, estando o jovem preocupado em concluir o seu curso" (CFE, 1979: 32).

Rodrigues (s.d.) considera que a decisão de extinguir o Projeto Rondon não esteve embasada em uma avaliação rigorosa das ações, programas, metodologias e resultados obtidos:

Faltou uma postura de estadista na sua avaliação, antes da decisão de extingui-lo. Não se entrou no mérito de sua expressão sócio-cultural; de sua dimensão geopolítica e estratégica (...).

Até o esvaziamento do princípio do trabalho voluntário tão escasso na postura cultural do brasileiro, e praticado intensamente pelos participantes do Projeto Rondon naqueles 22 anos - foi realizado sem a menor preocupação.

Ao ser extinto o Projeto Rondon, não se considerou, também, o desperdício de recursos financeiros que se estava praticando, com a dilaceração de seu espólio, pelo abandono completo, ou cessões improvisadas das instalações e equipamentos dos vinte e três 'Campi Avançados'. Além disso, vale lembrar o desperdício do capital humano que se pôs em prática ao 'encostar' em outros órgãos, para funções meramente burocráticas ou de finalidades completamente diferentes, os quadros técnicos da Fundação Projeto Rondon, desprezando-se todo o conhecimento e experiência acumulada por esses profissionais em 22 anos de trabalho com jovens, no incentivo ao trabalho voluntário, e com amplo conhecimento e vivência dos graves problemas sociais das regiões mais carentes do País, e que, além de tudo, gozavam de um alto conceito junto à sociedade como um todo.

Não se contesta o direito que tinham os novos responsáveis pela condução dos destinos do País de redirecionar e reformular muitos dos programas e procedimentos administrativos que eram adotados 
pelo Projeto Rondon, de modo a melhor adequá-los aos objetivos e interesses dos projetos que pretendessem implantar. A própria denominação de projeto mantida pelo movimento, e que seus participantes tanto fizeram questão de preservar, pressupunha que o mesmo era ainda um plano, um desígnio em andamento, e como tal, admitindo sempre a possibilidade e necessidade de constantes avaliações nos seus objetivos e formas de atuação, não apenas para a correção dos desvios que viessem a se constatar no seu desempenho, como também para a introdução de aperfeiçoamentos para que suas atividades melhor se ajustassem às circunstâncias conjunturais de cada momento, inclusive respondendo de forma mais adequada aos novos anseios e motivações que os jovens viessem a apresentar.

Antes de extingui-lo, o mínimo que se poderia esperar seria uma simples avaliação sobre os resultados de sua atuação. (...)

Entretanto, a ânsia 'revisionista' e o açodamento em procurar modificar ou acabar com tudo que pudesse ser classificado como 'entulho do autoritarismo, predominou sobre o mínimo de bom senso (...). (Rodrigues, s.d., s.p. - grifos do autor)

Durante a ditadura militar, além do Projeto Rondon, outro programa de interiorização - dessa vez específico para a área de saúde - foi implantado pelo governo brasileiro: o Programa de Interiorização das Ações de Saúde e Saneamento (Piass).

\section{O Programa de Interiorização das Ações de Saúde e Saneamento (Piass)}

Durante o governo militar, o Estado brasileiro estruturou sua atuação por meio de planos nacionais de desenvolvimento. O primeiro desses planos, conhecido como I PND e proposto para o período 1970 a 1974, estipulava a integração das ações de saúde aos programas de desenvolvimento como condição necessária para o crescimento econômico e social do país. O II PND, aprovado para o período 19751979, manteve o foco no desenvolvimento integrado, colocando a 'saúde' e a 'educação' como áreas prioritárias.

Como decorrência do II PND, o setor saúde foi reorganizado, com a criação do Sistema Nacional de Saúde (SNS), em 1975, por meio da lei n. 6.229, que definiu responsabilidades para os ministérios 
da Saúde, da Previdência e Assistência Social, da Educação, do Interior, do Trabalho, além de estados e municípios.

Dois meses depois, foi realizada a $5^{\mathrm{a}}$ Conferência Nacional de Saúde, que trouxe como um dos cinco temas centrais a extensão das ações de saúde às populações rurais. Em seu relatório final, constatavase que $50 \%$ da população do país vivia em áreas rurais, com precárias condições de vida e pouco acesso às ações de saúde e saneamento, enfatizando-se que:

Tal situação justifica a decisão do Ministério da Saúde de expandir as ações de saúde às populações rurais, de acordo com os recursos humanos disponíveis e a participação ativa da comunidade rural e das administrações municipais.

É indispensável, pois, fazer chegar a esta parcela apreciável da população que vive em áreas rurais, e à qual caberá destacada participação no setor agrícola e na colonização de novas áreas, um mínimo de prestação de serviços de saúde.

(...) seria utópico imaginar que a extensão das ações de saúde ao meio rural poderia ser obtida nas próximas décadas, por intermédio da atuação permanente e direta de médicos, enfermeiros, veterinários, engenheiros e dentistas, entre outros (...).

o caminho a seguir será recorrer aos auxiliares devidamente capacitados para exercerem uma série de funções delegadas, com supervisão e apoio periódico da enfermeira da área e do médico, para atividades assim programadas (...). (Brasil, 1975b: 256-258)

Esse diagnóstico e a estratégia proposta de compensar a falta de médicos e outros profissionais de nível superior com 'auxiliares devidamente capacitados' encontravam respaldo da Opas, cujo então diretor, no discurso de encerramento da Conferência, afirmou:

Temos o propósito de encarecer os governos a descartarem a idéia de 'qualidade primeiro, extensão depois'. As atividades de colaboração da organização [Opas] devem ter por finalidade estender a cobertura dos serviços de saúde a todas as pessoas às quais possam chegar, com todos os meios, a seu alcance. Só quando houver sido atingido este objetivo, é que se deve facilitar um serviço da mais alta qualidade possível, mas sem comprometer o objetivo imediato que é a cobertura total. (Brasil, 1975b: 317) 
Foi nesse contexto e "com a finalidade de implantar estrutura básica de saúde pública nas comunidades de até 20.000 habitantes e de contribuir para a melhoria do nível de saúde da população" que se deu a criação, em 1976, do Piass, pelo decreto n. 78.307 (Brasil, 1976a).

O Programa, inicialmente, focou a expansão dessa estrutura básica de saúde pública na Região Nordeste e posteriormente em todo o país, tendo como diretrizes:

I - ampla utilização de pessoal de nível auxiliar, recrutado nas próprias comunidades a serem beneficiadas;

II - ênfase na prevenção de doenças transmissíveis, inclusive as de caráter endêmico, no atendimento da nosologia mais freqüente e na detecção precoce dos casos mais complexos, com vistas ao seu encaminhamento a serviços especializados;

III - encaminhamento a serviços especializados;

IV - disseminação de unidades de saúde tipo miniposto, integradas ao sistema de saúde da região e apoiadas por unidades de maior porte, localizadas em núcleos populacionais estratégicos;

V - integração em nível dos diversos organismos públicos integrantes do Sistema Nacional de Saúde;

VI - ampla participação comunitária;

VII - desativação gradual de unidades itinerantes de saúde a serem substituídas por serviços básicos de caráter permanente. (Brasil, 1976a)

Os recursos destinados ao Piass provinham do Ministério da Saúde, do Fundo de Apoio ao Desenvolvimento Social (FAS), do Instituto Nacional de Alimentação e Nutrição (Inan) e do Programa de Integração Nacional (PIN). Estados e municípios também contribuíam, a título de contrapartida, com recursos recebidos para ações de saúde e saneamento do Fundo de Participação de Estados e Municípios (FPE e FPM). A Previdência Social também destinou recursos ao Programa, cujo decreto de criação definiu que o então Instituto Nacional da Previdência Social (INPS) e o Fundo de Assistência e Previdência ao Trabalhador Rural (Funrural) deveriam remanejar para o Piass os recursos destinados à assistência médica nas áreas de atuação do Programa. 
Coordenado por um Grupo Executivo Interministerial (Gein), composto pelos ministérios da Saúde, Previdência, Interior e pela Secretaria de Planejamento da Presidência da República, o Piass foi criado com duração prevista de quatro anos (até dezembro de 1979). Posteriormente, foi proposta e aprovada sua expansão para todo o país, estendendo-se esse prazo para 1985.

Além da implantação de unidades básicas de saúde, o Programa previa, ainda, dois outros tipos de ação: 1) a instalação de saneamento básico, por meio de sistemas simplificados de abastecimento de água, remoção de dejetos e destino do lixo; 2) o desenvolvimento de "ações coordenadas com programas de desenvolvimento sócio-econômico, sobretudo no que se refere ao aumento da disponibilidade e adequada utilização de alimentos essenciais" (Gein/Piass, 1977).

Para executar o conjunto de ações previstas, o Piass recorria à ampla utilização de pessoal de nível médio e elementar, incluindo auxiliar de saúde, auxiliar de saneamento, inspetor de saneamento, atendente de enfermagem e outros, recrutados nas próprias localidades de atuação e devendo trabalhar sob supervisão constante, com apoio técnico e administrativo das unidades de saúde mais complexas.

O Programa foi estruturado com uma lógica modular de organização, cujo componente essencial era o 'módulo básico', definido como "um conjunto formado por Postos DE SAúde localizados em comunidades rurais, apoiados por uma unidade de maior porte, geralmente um CENTRO DE SAÚDE, situado na sede do município". (ST/ Gein/Piass, 1980). O posto de saúde constituía-se como uma "unidade simples operada por Auxiliar de Saúde de nível elementar, especialmente treinado para a execução de ações básicas de saúde", e o centro de saúde, como "unidade mais complexa, com atendimento médico permanente e laboratório básico, responsável pela supervisão e apoio aos Postos de Saúde" (ST/Gein/Piass, 1980).

Em geral, o módulo básico correspondia a um município e era composto por um centro de saúde, dimensionado para atender a 6.000 habitantes e dar apoio logístico e atendimento de referência para até três postos de saúde, localizados em distritos, vilas e povoados e preparados para atender no máximo 2.000 habitantes, cada um.

A execução do Piass esteve a cargo das secretarias estaduais de saúde, com participação das companhias estaduais de saneamento, das secretarias de obras, das prefeituras e de organizações comunitárias. 
O programa gerou um expressivo crescimento da rede ambulatorial que registrou, entre 1975 e 1984, um aumento de 1.255\% (Mendes, 1993). Essa expansão e as condições políticas favoráveis ao Programa - que além de atender as parcelas desassistidas da população ainda o fazia com importante racionalização de recursos - fizeram com que o Piass fosse "deixando de ser uma proposta essencialmente de programa complementar, 'marginal' dentro do quadro da atenção à saúde do país, para tornar-se um projeto de prestação de serviços alternativa, abrangendo o atendimento a parcelas majoritárias da população" (Rosas, 1981: 137).

Na avaliação de Rosas (1981: 137), essa passagem "de programa complementar a modelo de prestação de serviço em condições de disputar a hegemonia do setor com o modelo previdenciário" pode ser entendida como:

conseqüência natural da busca de alternativas diante da crise do modelo previdenciário (baseado na compra de serviços) (...). Essa crise é agravada com o crescimento progressivo das pressões sociais, resultante de maior organização e poder de pressão das camadas sociais (...) reivindicando, entre outras coisas, a ampliação da assistência à saúde (...).

Ainda assim, o Relatório de situação, de 1981, elaborado pelo Ministério da Saúde, admitia que o mais difícil na implantação do Programa era a "manutenção adequada da rede de unidades em funcionamento e isto subentende que as unidades de saúde devem estar prestando serviços permanentemente. A população deve ter acesso aos serviços e estes serviços devem ser de boa qualidade" (Brasil, 1981: s.p.).

Além disso, ao basear a extensão de cobertura não na interiorização de médicos, mas no trabalho de pessoal auxiliar, o Piass viu comprometidas as chances de ampliar mais do que a rede de serviços básicos, mas também a qualidade da atenção à saúde. Felipe (1987: 488-489) destaca alguns limites e incongruências do Programa:

Havia um distanciamento entre o discurso moderno e a viabilidade operativa, permeada por estruturas administrativas viciadas, afeitas ao clientelismo e à inoperância. O eficientismo propunha 'custos compatíveis' ou 'suportáveis' em nome da replicação de serviços de baixa qualidade, restritos à ampliação 
de uma rede de centros e postos de saúde pouco resolutiva. A utilização de pessoal leigo, após treinamentos sumários e descontínuos, significava a decomposição da ação assistencial segundo graus de complexidade: ações mais simples, supostamente repetitivas, executadas por trabalhadores de saúde menos qualificados, preferencialmente entre as populações sem tradição assistencial e desorganizadas, portanto menos exigentes. O resultado foi a instituição de uma medicina pobre, para pobres.

A estratificação do atendimento, conforme a inserção das camadas sociais no mercado produtivo, e o beco sem saída da rede primária sem referência, foram rechaçados pela população, que repudiou tal estrutura. $\mathrm{O}$ desaparecimento ou a agonia dos serviços, superada a excitação do processo de implantação, acabou sendo trágica, com o desperdício de capital social inativado em milhares de ambulatórios.

Como aspectos positivos do Programa, o mesmo autor destaca:

O avanço, a nível de concepção, passou pela ambição em termos de cobertura de massa e abrangência da intervenção realizada, que incorporou ações de saneamento básico. A implantação de sistemas simplificados de abastecimento de água em comunidades rurais praticou o reconhecimento de que a saúde se liga à qualidade de vida. Também a realização maciça de obras através dos governos municipais, com êxito considerável, contribuiu para o recuo dos preconceitos quanto à descentralização. A administração municipal diluiu-se enquanto locus privilegiado de dispersão de recursos públicos.

A abrangência nacional, com a extensão do Piass a outras regiões do País, fez aglutinar segmentos interessados no fortalecimento do setor público na prestação de serviços de saúde. (Felipe, 1987: 488-489)

Esses aspectos foram decisivos para o surgimento de novas proposições para o setor, estimuladas, ainda, pela crise do financiamento previdenciário e pela recessão econômica. Mas na prática a viabilização de novas formulações "mostrava-se difícil, pelo comprometimento institucional com o modelo engendrado, que implicou no desmonte ou estagnação dos serviços públicos (...)" (Felipe, 1987: 489). 
Apesar da vitalidade e da pressão dos setores interessados na manutenção do modelo previdenciário de atenção à saúde ainda terem se mostrado dominantes, essa nova orientação se consagrou na $7^{\mathrm{a}}$ Conferência Nacional de Saúde, realizada em 1980, que teve como tema central "Extensão das ações de saúde através dos serviços básicos". $\mathrm{Na}$ Conferência, o Ministério da Saúde, ao apresentar suas diretrizes, definiu os serviços básicos de saúde como "núcleo axial e ordenador" de suas ações e propôs a elaboração de um Programa Nacional de Serviços Básicos de Saúde (Prev-Saúde), de caráter interministerial, que deveria orientar todos os demais programas e atividades do ministério. Segundo essas novas diretrizes, o Piass se constituiria como uma "fase inicial" do Prev-Saúde, devendo a ele se integrar "como componente rural e de pequenos centros" (Brasil, 1980).

No entanto, o próprio Prev-Saúde não saiu do papel e com ele levou o Piass. Mendes (1993: 34-35) resume o que ocorreu:

O projeto [Prev-Saúde] tinha como objetivo básico a extensão máxima da cobertura, para o que apresentava temáticas discursivas como regionalização e hierarquização, participação comunitária, integralização das ações de saúde, uso de técnicas simplificadas, utilização de pessoal auxiliar e inclusão do setor privado no sistema.

A primeira versão, feita em agosto, incorporava, portanto as diretivas de organismos internacionais e do movimento sanitário, mas, como fruto da transição democrática, continha o viés de elaboração tecnocrática.

As restrições que, num primeiro momento, sofre dentro da própria burocracia estatal, remete a uma segunda versão, dita de setembro, que a reduz a uma proposta racionalizadora do modelo vigente.

O projeto, colocado em debate público, sofreu contestações de nítido caráter ideológico de todos os grupos interessados na questão da saúde e é então analisado pela Ciplan e encaminhado à Comissão de Saúde da Câmara dos Deputados de onde não mais sairia.

Encerrava-se, assim, a trajetória do Piass, já como conseqüência dos embates que a arena política do processo de redemocratização propiciava. A discussão sobre o setor saúde, por meio de seus respectivos grupos de interesse, chegava finalmente ao Poder Legislativo, que passaria a ter papel decisivo nos rumos do setor daí em diante. 


\section{Estratégias Pós-Redemocratização}

Em 1978, ainda durante o governo militar, começa o processo de redemocratização do país, com o fim do Ato Institucional n. 5 (AI5), a gradual restituição dos direitos democráticos, a decretação da lei da Anistia - concedendo o direito de retorno ao Brasil para os exilados e condenados por crimes políticos - e a aprovação, pelo governo, da lei que restabeleceu o pluripartidarismo no país, em 1979.

Nesse novo contexto político, foram criadas duas intervenções com foco na interiorização: o Programa de Interiorização do Sistema Único de Saúde (Pisus) e o Programa de Interiorização do Trabalho em Saúde (Pits).

\section{O Programa de Interiorização do Sistema Único de Saúde (Pisus)}

O Pisus foi proposto em novembro de 1993, ou seja, cinco anos após a promulgação da Constituição de 1988, que criou o Sistema Único de Saúde (SUS). No documento que apresenta o Programa, criado pelo Departamento de Desenvolvimento, Controle e Avaliação dos Serviços de Saúde, da então Secretaria de Assistência à Saúde do Ministério da Saúde, o problema a ser enfrentado e a estratégia proposta são assim contextualizados:

Estamos em uma época, com princípios constitucionais em defesa do direito universal à saúde: a descentralização, a responsabilidade tripartite das três esferas de governo, a democratização da gestão e a participação popular. É toda uma legislação de suporte de reforma do Estado. A proposta ora apresentada insere-se neste contexto. Estamos partindo para uma solução de coparticipação das três esferas de governo tendo como base a municipalização. Fugimos da idéia de um programa verticalizado e mantido através da tutela federal. Este programa está dentro do princípio da cooperação técnica e financeira da União e estados para que os municípios, que não dispõem de serviços de saúde, tenham condições de assumirem esta competência constitucional (...).

Temos certeza de que os fatores que sempre condicionaram a presença ou não dos serviços de saúde em determinado local, não estarão de per si vencidos com esta proposta. Mas apostamos 
igualmente, que através dela poderemos estar minimizando o problema. Não estamos defendendo apenas a interiorização do profissional médico, mas sim de uma equipe mínima de saúde, com suporte através de uma pequena unidade de saúde com instalações mínimas e equipamentos essenciais. Não será a simples presença de um médico que fará a interiorização da saúde. Entretanto, a história de nosso país mostra que foi a presença do médico, por primeiro, quem garantiu, na maioria dos municípios brasileiros, a interiorização de outros profissionais de saúde. A partir do médico foram surgindo outras necessidades e respostas: a unidade de saúde, os profissionais de apoio, os demais profissionais, até se constituir uma equipe completa.

Se hoje o Ministério da Saúde tem como seu projeto principal o cumprimento da lei e a efetivação da descentralização, é no bojo deste projeto que se encaixa este programa. Não é mais um programa paralelo e descolado do restante: faz parte integrante da descentralização e da municipalização. Enquadra-se na proposta de fazer com que haja no município um gestor único que se habilita a, paulatinamente, ir assumindo suas funções gerenciais sob o controle da sociedade à qual serve (Brasil, 1993b: 4-5)

O Pisus foi estruturado em quatro subprogramas: 'Unidades de Pronto Atendimento'; 'Interiorização do Médico'; 'Interiorização do Enfermeiro'; 'Agente Comunitário de Saúde'.

O subprograma de 'Unidades de Pronto Atendimento' tinha como objetivo prover uma unidade de saúde, em cada município contemplado, com condições mínimas de funcionamento, e equipada com sala de imunização, consultório médico, sala de enfermagem, sala de emergência, sala de parto, mínimo de dois leitos de observação, e instalações de apoio. Este subprograma pretendia que paulatinamente fossem acoplados outros equipamentos, como consultório odontológico, laboratório, raios $\mathrm{X}$ etc.

Os custos para a reforma ou construção de unidades de saúde ficariam a cargo do Ministério da Saúde e dos Estados, na proporção de 50\% para cada um. "A Funasa, que mantém inúmeros serviços de saúde em regiões carentes, terá responsabilidade de colocar sua rede física própria, em condições de funcionamento como pré-requisito para o processo de descentralização em curso" (Brasil, 1993b: 13). 
A meta do subprograma de 'Interiorização do Médico' consistia na fixação de pelo menos um médico, com residência, no respectivo município participante do programa. Os formuladores do Pisus não desconheciam a dificuldade de alcançar esta meta:

Muitos alegam que dificilmente se vá conseguir a presença do médico como morador do local. Acham que questões culturais, sociais e o próprio acesso às facilidades do progresso acabam por interferir, se não no médico, com certeza em seus familiares, de modo a se constituir em óbice irremovível a sua fixação nestes locais. Isto pode ser verdadeiro na tese e na prática, mas vamos investir na criação das condições técnicas mínimas para neutralizar estes óbices. Em primeiro lugar: condições de instalações físicas, interiorização de equipe mínima e pagamento justo pelo ônus. (Brasil, 1993b: 7-8)

Para viabilizar esse 'pagamento justo', o Ministério da Saúde propunha-se a garantir ao gestor municipal os recursos financeiros para a remuneração de honorários aos médicos. Mediante um contrato formal entre o município e o profissional, a remuneração se daria pela modalidade de pagamento por produção. Para isso, o Ministério se comprometia a realizar o pagamento por produção de consultas pelo dobro do valor vigente da tabela SUS.

No caso de ocorrer a interiorização de uma dupla de médicos, o contrato e a remuneração deveriam ser divididos, com cargas horárias de 20 horas semanais. "A garantia do Ministério da Saúde é de pagamento deste total de consultas em valor duplo. O gestor municipal poderá fazer forma de pagamento por produtividade baseado nos valores de tabela de outros procedimentos" (Brasil, 1993b: 8).

Os subprogramas 'Interiorização do Enfermeiro' e 'Interiorização do Agente Comunitário de Saúde' tinham como objetivo garantir a presença desses dois profissionais na equipe. A remuneração dos enfermeiros também deveria se dar por meio da transferência de "recursos de produção suficientes, baseados em valores das ações de enfermagem, para que se garanta ao gestor municipal a possibilidade de pagar por contrato ao enfermeiro um mínimo de 10 salários mínimos" (Brasil, 1993b: 9). No caso dos agentes comunitários de saúde, os municípios teriam que efetuar um contrato por até três anos, com recursos também provenientes de pagamento por produção, com base na tabela de ações 
específicas dos agentes, garantindo-se remuneração mínima de um salário mínimo.

Caberia aos municípios garantir a moradia para médicos e enfermeiros, complementar o pessoal mínimo necessário para a unidade de saúde (auxiliar de serviços gerais, auxiliar de escritório e motorista e/ou barqueiro) e o transporte intermunicipal de pacientes, por meio de ambulância ou barco.

As secretarias estaduais de saúde teriam a responsabilidade de monitorar os municípios, "oferecendo todo o apoio e cooperação técnica. As SES estarão presentes desde a implantação, na habilitação para que estes municípios assumam algum nível de gestão segundo a NOB 01/93 e no acompanhamento através de equipe técnica" (Brasil, 1993b: 14). Também deveriam garantir todo o material de consumo, incluindo medicamentos, vacinas e material médico e de enfermagem.

A implantação do Pisus estava prevista para ocorrer inicialmente na Região Norte, cobrindo 398 municípios localizados nos estados do Acre, Amapá, Amazonas, Pará, Rondônia, Roraima e Tocantins, totalizando uma população de 2.035.000 habitantes (Brasil, 1993c:1). Pretendia-se que após uma avaliação da implantação nestes estados, o Programa fosse estendido, em um prazo máximo de 180 dias, para outras regiões que apresentassem a mesma carência. Estes novos municípios seriam selecionados com a intermediação das secretarias estaduais de saúde:

Os Estados que estiverem interessados neste programa apresentarão estudos ao Ministério da Saúde demonstrando os municípios que não dispõem de nenhum médico, ou de apenas um médico (situação à qual estenderemos o Programa), e aqueles que dispõem de distritos, distantes da sede, que não têm médico. A primeira e segunda situação serão atendidas de pronto e a questão dos distritos dependerá de avaliação a partir do relatório apresentado pelos Estados.

As SES, igualmente, apresentarão relatórios sobre a rede física nestes locais. A existente e em que condições se encontra e a não existente qual seria a proposta de edificação. Levantamento de custos e cronograma de obras com a contrapartida estadual. (Brasil, 1993b: 17)

No entanto, os formuladores do Pisus não atentaram para os riscos que a efetiva implantação do Programa corria, por ter sido proposta no 
último ano do mandato do governo vigente. Com as eleições presidenciais de outubro de 1994, ou seja, 11 meses após o anúncio do Programa, o Pisus foi abandonado como estratégia de intervenção pelo novo governo, tendo sido extinto pouco mais de um ano depois de sua criação.

Não houve pressão social para que o Programa fosse mantido, uma vez que não havia sequer sido efetivamente implantado. Da mesma forma, faltou apoio político para evitar sua extinção, o que pode ser explicado, em parte, por se tratar de uma proposta originária de outra gestão e pelo baixo grau de articulação com instâncias decisivas para a implantação de estratégias de interiorização, tema que, como já vimos, admite inúmeras e distintas concepções políticas e de compreensão do problema.

$\mathrm{Na}$ avaliação de um dos atores entrevistados em estudo realizado por Goulart (2002: 117), "foi uma experiência que fracassou por ter sido articulada junto aos Estados e não diretamente com os municípios, ao contrário do Pacs e do próprio PSF, que tiveram tal componente bem definido e, por isso mesmo, outra trajetória".

\section{O Programa de Interiorização do Trabalho em Saúde (Pits)}

Foi com o intuito de promover maior e melhor distribuição de médicos e enfermeiros no país, aperfeiçoar a formação desses profissionais e impulsionar a atenção básica via Programa de Saúde da Família (PSF), que o Ministério da Saúde criou, em 2001, o Programa de Interiorização do Trabalho em Saúde (Pits) (Brasil, 2001a).

A proposta foi elaborada por grupo de trabalho criado pela portaria n. 1.162, de 18 de outubro de 2000, constituído por representantes dos ministérios da Saúde e da Educação, dos conselhos nacionais de secretários estaduais e municipais de saúde (Conass e Conasems), da Opas, do Programa Comunidade Ativa e de entidades ligadas às áreas de enfermagem e de medicina (Conselho Federal de Medicina - CFM; Associação Médica Brasileira - AMB; Conselho Federal de Enfermagem - Cofen; Associação Brasileira de Enfermagem - Aben; Associação Brasileira de Educação Médica - Abem e Direção Executiva Nacional dos Estudantes de Medicina - Denem) (Brasil, 2000).

O Programa foi instituído pelo decreto n. 3.745, de 5 de fevereiro de 2001, e regulamentado pela portaria n. 227, de 16 de fevereiro de 
2001 (Brasil, 2001a, 2001b). Contando com uma coordenação nacional no Ministério da Saúde e coordenações estaduais, adotou a mesma estratégia de atuação do PSF (inclusive na composição das equipes, formadas por um médico, um enfermeiro, um auxiliar de enfermagem e quatro a cinco agentes comunitários de saúde). As coordenações estaduais contaram com representantes dos pólos de capacitação do $\mathrm{PSF}^{8}$ das representações estaduais do PSF e dos conselhos de Secretários Municipais de Saúde (Cosems).

O Pits propunha-se a estimular a ida de médicos e enfermeiros para os municípios mais carentes e distantes, por meio de incentivos financeiros e de formação profissional, assim previstos na portaria $\mathrm{n}$. 227 (Brasil, 2001b):

- curso introdutório de preparação para o desempenho de suas atividades junto ao Programa, com carga horária de 80 horas;

- tutoria e supervisão continuadas, participação em cursos, material instrucional e bibliográfico;

- curso de especialização em saúde da família, com carga horária de 360 horas, de forma presencial e a distância;

- condições adequadas para o desempenho de suas atividades, tais como instalações, equipamentos e insumos;

- certificado de participação no Programa;

- bolsa mensal, a título de incentivo e ajuda de custo, variando de $\mathrm{R} \$ 4.000,00$ a $R \$ 4.500,00$, para médicos, e de $\mathrm{R} \$ 2.800,00$ a $\mathrm{R} \$$ 3.150,00, para enfermeiros, de acordo com critérios de distância do município de atuação para a capital e vias de acesso, assim definidos pela Coordenação Nacional;

- seguro obrigatório de vida e acidentes pessoais correspondente ao período de participação no Programa;

- moradia, alimentação e transporte para o desenvolvimento de suas atividades.

8 Os pólos de capacitação se destinam à formação, capacitação e educação continuada de recursos humanos para o PSF. Em geral, estão vinculados a universidades e estruturados a partir de uma ou mais instituições de ensino. Sua criação e funcionamento se dão mediante a celebração de convênios entre o Ministério da Saúde, as secretarias estaduais e/ou municipais de saúde e as instituições formadoras. 
A implantação das bolsas para remuneração dos médicos e enfermeiros, com duração de um ano e renováveis por mais um, deu-se mediante a celebração de convênio entre o Ministério da Saúde e o Conselho Nacional de Desenvolvimento Científico e Tecnológico (CNPq).

O curso de especialização em Saúde da Família foi encomendado aos pólos de capacitação do PSF e instituições de ensino superior, tendo como objetivos:

- capacitar os profissionais para o processo de gestão local, com ênfase na concepção de saúde coletiva, seguindo os princípios do SUS;

- aprimorar a capacidade para o trabalho em equipe e multidisciplinar na perspectiva da abordagem integral dos problemas de saúde;

- desenvolver conteúdos programáticos que favoreçam o pronto e adequado diagnóstico de doenças prevalentes nas respectivas localidades de trabalho;

- aperfeiçoar a atuação clínica e gerencial de ações para uma apropriada atenção à saúde da criança, da mulher, do adulto e do idoso, mediante uma abordagem integral e familiar. As diretrizes pedagógicas centram-se numa metodologia crítico-reflexiva, em que o aluno desempenha um papel ativo na construção de seu próprio conhecimento e atua como agente de mudança. (Brasil, 2001e: 7)

O curso foi realizado em universidades das capitais dos respectivos estados de localização dos municípios. Os gastos com transporte e diárias para o deslocamento dos médicos e enfermeiros integrantes do Pits ficaram a cargo do Ministério, que também arcou com o seguro de vida e de acidentes pessoais para os profissionais.

Além do curso, o Programa previa tutoria e supervisão para os médicos e enfermeiros, realizadas via Internet e/ou por visitas periódicas de acompanhamento. O Ministério da Saúde deveria arcar com o pagamento dos tutores e com os custos de implantação do acesso à Internet e do material didático (livros de enfermagem e medicina sobre atenção básica e ambulatorial). A remuneração dos tutores e supervisores integrava o mesmo convênio com o CNPq celebrado para o pagamento dos profissionais. A tutoria e a supervisão deveriam se dar ao longo dos 12 meses de atuação dos médicos e enfermeiros no Programa, prevendo- 
se um tutor médico e um tutor enfermeiro para cada grupo de dez profissionais.

A habilitação dos municípios no Programa se deu mediante a assinatura de termo de compromisso entre a Prefeitura e a Secretaria de Estado de Saúde, homologado pelo Ministério. ${ }^{9}$

Como estímulo para os municípios implantarem o Pits, o Ministério da Saúde instituiu, por meio da portaria n. 1.069, de 18 de julho de 2001, incentivo financeiro de dez mil reais, por equipe implantada, além de determinar, pela mesma portaria, que cada município também recebesse o Incentivo à Assistência Farmacêutica Básica, vinculado ao PSF e que fôra criado pela portaria n. 343 , em março do mesmo ano (Brasil, 2001c).

A contrapartida dos municípios compreendeu moradia, alimentação e transporte local para os médicos e enfermeiros, além da disponibilidade de unidade básica de saúde para o desenvolvimento das atividades. Deveriam assegurar, ainda, o quantitativo de auxiliares de enfermagem e de agentes comunitários e suporte para a referência e contra-referência.

O Ministério da Saúde realizou campanha publicitária em jornais, rádios e televisões para divulgar o Pits e convocar os profissionais para o processo seletivo. Essa seleção se deu por meio de avaliação curricular e entrevista. As inscrições foram efetuadas exclusivamente pela Internet, com o preenchimento de um formulário curricular, pontuado eletronicamente segundo critérios pré-definidos por Comissão Nacional de Seleção, instituída pela portaria n. 6, de 21 de fevereiro de 2001 (Brasil, 2001d). No ato da inscrição, os candidatos tinham que primeiro dar o aceite eletrônico ao Regulamento do Programa (Brasil, 2001b), no qual constavam direitos e deveres dos profissionais, do Ministério da Saúde, dos estados e dos municípios.

Também na inscrição, a página eletrônica construída especificamente para o processo seletivo permitia que os candidatos tivessem acesso a informações geográficas, demográficas, econômicas, sociais e de saúde sobre cada município. Com base nesse conjunto de informações, o candidato deveria escolher os municípios de sua preferência, que seria obedecida mediante a ordem de classificação obtida no processo seletivo.

9 A íntegra do termo de compromisso encontra-se disponível em Brasil (2001e). 
No primeiro ano, o número de municípios participantes foi de 151 (Brasil, 2001e) selecionados segundo os seguintes critérios (Brasil, 2001a):

- população de até 50 mil habitantes;

• não dispor do PSF;

- apresentar coeficiente de mortalidade infantil igual ou superior a 80/1.000 nascidos vivos;

- ser área de prioridade para o controle de malária, tuberculose ou hanseníase;

- apresentar indicador de consulta médica/habitante/ano igual ou inferior a um;

- ser participante dos programas governamentais Comunidade Ativa ou Projeto Alvorada, de combate à pobreza e à exclusão social.

No primeiro processo seletivo, realizado em fevereiro de 2001, o Pits registrou 15.488 inscrições, sendo 2.370 médicos $(15,3 \%)$ e 13.118 enfermeiros (84,7\%). Foram oferecidas 300 vagas para médico e 300 para enfermeiro (Brasil, 2001e).

Foram classificados para as entrevistas, pela análise curricular eletrônica, 1.200 médicos e 1.200 enfermeiros, correspondendo a quatro candidatos por vaga, por categoria profissional. Observou-se um absenteísmo de $45 \%$ dos candidatos, o que, aliado à falta de comprovação curricular, levou a coordenação nacional a convocar, na sequiência da classificação, mais 853 profissionais (777 enfermeiros e 76 médicos), totalizando 3.253 candidatos (Brasil, 2001e). Mais uma vez, registrou-se não comparecimento à entrevista de seleção, falta de comprovação curricular, além de desistências após a aprovação final.

Foram lotados 421 profissionais ( $70,1 \%$ dos 600 previstos), sendo 181 médicos (60,3\% das 300 vagas) e 240 enfermeiros ( $80 \%$ dos 300 previstos). O número de equipes por município variava segundo o número de habitantes e a densidade demográfica. Além dos municípios com equipes incompletas (ou seja, sem médico e com enfermeiro), outros vinte não foram escolhidos por qualquer dos profissionais lotados, sendo a maioria localizada na Região Norte, ficando, conseqüentemente, sem equipes (Brasil, 2001e). 
A população coberta pelo Programa, em 2001, chegou, oficialmente, a 1.536.827 habitantes (Brasil, 2002e). No entanto, subentende-se que esse número seja menor, já que não foi subtraída a população dos municípios que ficaram sem profissionais.

Em outubro de 2001, devido a desligamentos e desistências de profissionais e a fim de recompor as vagas existentes, foi feito um segundo processo seletivo para médicos e enfermeiros. Foram preenchidas 34 vagas para médico e 29 para enfermeiro (Brasil, 2002f).

Novos desligamentos e desistências ocorreram nos meses seguintes. Com isso, ao se completar um ano de atividade dos profissionais no Pits (junho de 2002), a ocupação do total de vagas para médicos diminuiu de 181 (60,3\% das 300 vagas) para 165 (54,1\% das vagas). No estado do Amazonas, o percentual de preenchimento das vagas para médicos foi de apenas 14\%. Já a lotação de enfermeiros passou de $77 \%$ para $81,3 \%$ de preenchimento das vagas e só não foi de $100 \%$ porque vários prefeitos não aceitaram equipes sem médico (Brasil, 2002f).

Oficialmente, a população coberta passou para 1.590.317, o que representaria um incremento de 3,5\% em relação ao início do Programa (que teria sido de 1.536.827 hab., conforme já referido). Entretanto, a mesma observação anteriormente feita é válida também aqui, subentendendo-se que essa cobertura tenha sido menor do que a divulgada, já que apenas $54,1 \%$ das vagas para médicos foram ocupadas.

O segundo ano do Programa de Interiorização do Trabalho em Saúde teve início, oficialmente, em agosto de 2002. O Ministério da Saúde publicou duas novas portarias (n. 758 e n. 1.695), com novos dispositivos de regulamentação, a fim de promover ajustes e adequações e ampliar as normas disciplinares (Brasil, 2002b, 2002c).

Também foram alterados os critérios de elegibilidade dos municípios. Houve mudança no recorte do número máximo de habitantes, que passou de 50.000 para 20.000. A Região Norte foi dispensada da exigência de não possuir o PSF. O critério de mortalidade infantil passou a variar de acordo com a região de localização do município. Na Região Norte, esse coeficiente ficou estabelecido em 30 por mil nascidos vivos, com exceção do estado de Tocantins, que ficou em 50/1.000, mesmo coeficiente definido para o Centro-Oeste e para o estado de Minas Gerais (único da região Sudeste contemplado pelo Programa, assim como ocorrera no primeiro ano). Para o Nordeste foi estabelecido coeficiente mínimo de 60 por mil nascidos vivos. Outra 
condição passou a ser a ausência de leito hospitalar no município, não exigido para a Região Norte. Os demais critérios permaneceram os mesmos (Brasil, 2002e).

O Ministério abriu novas inscrições para profissionais interessados em participar do Pits e selecionou novos municípios, além de estimular os de 2001 a renovarem sua participação. O novo processo seletivo obedeceu à mesma metodologia do ano anterior, tendo sido registradas 11.635 inscrições, sendo 9.916 enfermeiros e 1.719 médicos (Brasil, 2002e).

O número total de municípios com vagas passou para 216. Desse total, somente pouco mais da metade (56,5\%), ou seja, 122 municípios, contavam com profissionais lotados, em junho de 2002 (Brasil, 2002e). Esse número deve-se ao não preenchimento de vagas durante o processo seletivo (absenteísmo na entrevista e falta de comprovação curricular) e desistências e desligamentos ao longo do Programa, tanto de profissionais quanto de municípios.

Os prefeitos e os profissionais que já participavam do Pits desde 2001 foram consultados, pela coordenação nacional, em junho de 2002, sobre o interesse em permanecer no Programa. Cerca de 30\% dos municípios e $17 \%$ dos profissionais não responderam à consulta. Dentre os que responderam, o percentual de municípios que manifestaram interesse em prorrogar sua participação por mais um ano foi de 95,5\%, muito próximo do percentual dos profissionais, que foi de quase $93 \%$ (Brasil, 2002e). Entretanto, ao analisar o banco de dados do Programa, verifica-se que esses profissionais eram, em sua quase totalidade, enfermeiros (Maciel Filho, 2007).

Com as eleições presidenciais de outubro de 2002 e a conseqüente mudança de ministro em janeiro de 2003, o Pits tornou-se objeto de análise por parte da nova equipe. Foi realizado um Seminário Nacional de Avaliação, em junho de 2003, cujo resultado levou o Ministério à decisão de iniciar um processo de reformulação, com o objetivo de integrálo às estruturas do SUS, particularmente à atenção básica, desencadeando a transição do Programa para os sistemas municipais de saúde. A intenção era assegurar a permanência das equipes nos municípios, que foram estimulados a implantar ou ampliar o PSF.

Assim, em 2003, foi incluído um número menor de novos municípios, mantendo-se os que já faziam parte do Programa e tinham interesse em continuar. Da mesma forma, foram abertas menos vagas no processo seletivo do que nos anos anteriores, preferindo-se estimular 
a permanência dos profissionais aprovados em 2002 e dos poucos remanescentes de 2001, por meio da renovação por mais um ano. Esse estímulo incluía, já desde 2002, um acréscimo de $10 \%$ do valor da bolsa recebida.

Em julho de 2004, o Programa foi declarado oficialmente encerrado. Apenas alguns poucos profissionais ainda se encontravam nos municípios, e à medida que foram completando um ano no Programa, foram retornando, paulatinamente, para suas cidades de origem.

Ao longo dos três anos de implantação do Pits, foram contemplados cerca de 300 municípios, aí incluídos também os que não concluíram o período mínimo de um ano de participação. Foram aplicados no primeiro ano $R$ \$ 36,1 milhões e alocados mais $R$ \$ 70 milhões no orçamento 2002/ 2003 (Brasil, 2002e).

A análise do Pits, como estratégia de intervenção para enfrentar o problema da má distribuição de médicos no país, é realizada no capítulo seguinte. 